\title{
Políticas públicas para pessoas com deficiência no Brasil: o desafio da inclusão social ${ }^{1}$
}

\section{Políticas públicas para personas con incapacidad en Brasil: el desafío de la inclusión social}

\author{
Public policies for disabled people in Brazil: The challenge of social inclusion
}

\author{
Maria de Nazaré de Oliveira Fraga', Antonia Félix de Sousa" \\ ${ }^{1}$ Artigo construído a partir da dissertação de Mestrado da segunda autora. \\ ' Enfermeira. Doutora em Enfermagem. Docente do Curso de Mestrado em Avaliação de Políticas Públicas da Universidade Federal do Ceará. \\ Email: mnofraga@ufc.br. \\ "Licenciada em História. Mestre em Avaliação de Políticas Públicas pela Universidade Federal do Ceará. Coordenadora do Programa de \\ Educação e Saúde do Projeto Dom Helder Camara - SDT/MDA/FIDA. Email: antonia@dom.gov.br.
}

\begin{abstract}
RESUMO
A redemocratização do Brasil produziu muitas demandas pela universalização de direitos sociais. A situação vivenciada pelas pessoas com deficiência emergiu com vigor nesse contexto. Este trabalho tem como objetivo refletir sobre como a sociedade brasileira vem se comportando em relação a essas pessoas, tomando por base as políticas públicas voltadas a esse segmento e como suporte para análise o princípio da inclusão social. Constatamos que a nova legislação e as entidades das pessoas com deficiência fizeram esse problema emergir como uma questão social e relacional. Hoje está em franca construção a fase de autonomia das pessoas com deficiências, havendo resquícios dos paradigmas anteriores. Essa transição paradigmática que é mundial faz emergir sociedades que reconheçam as necessidades desse segmento de pessoas, cujos direitos vêm sendo crescentemente assegurados pela articulação de diversos movimentos e redes sociais, e pela re-orientação das ações de governos e de organismos internacionais.
\end{abstract}

Descritores: Políticas públicas; Pessoas com deficiências; Inclusão social.

\begin{abstract}
The situation experienced by disabled people emerged strongly in this context. This study aims to reflect about how Brazilian society has been acting concerning these people, based on public policies focused on this segment and is a support for the analysis of social inclusion. We noticed that the new legislation and the institutions for disabled people made this problem emerge as a relationship and social question. Nowadays the autonomy of disabled people is increasing, although there are traces of old paradigms. This paradigmatic change, that happens worldwide, creates societies that recognize these people's needs, whose rights have been increasingly guaranteed by several movements and social groups, and by the re-orientation of governmental actions and international entities.
\end{abstract}

Descriptors: Public policies; Disabled people; Social inclusion.

\section{RESUMEN}

La redemocratización del Brasil producció muchas búsquedas por la universalización de derechos sociales. La situación vivida por las personas con deficiencia emergió con vivacidad en ese contexto. Este trabajo tiene como objetivo reflejar sobre como la sociedad brasileña se comporta en relación a esas personas, teniendo como base las políticas públicas voltadas para éstos fragmentos y como soporte para análisis del principio de la inclusión social. Constatamos que la nueva legislación y las entidades de las personas con deficiencia hicieron ese problema emergir como una cuestión social y relacional. Hoy, se queda una construcción de la fase de autonomía de las personas con deficiencia, habiendo resquicios de los paradigmas anteriores. Esa transición paradigmática, que es mundial, haz emergir sociedades que reconozcan las necesidades de ese fragmento de personas, cuyos derechos se viene creciendo y todavía es asegurado por la articulación de diversos movimientos y redes sociales, y por la reorientación de las acciones de gobiernos y de organismos internacionales.

Descriptores: Políticas públicas; Personas con Discapacidad; Inclusión social. 


\section{NTRODUÇÃO}

No Brasil, principalmente no decorrer da década de 80 do século $X X$, o processo de redemocratização, de fortalecimento da organização popular e a emergência de novos atores sociais, produziram a ampliação das mais diversas demandas sobre o Estado, exigindo a universalização do acesso a diversos direitos sociais, entre os quais se destacou a defesa pelo direito à saúde como direito universal e dever do Estado ${ }^{(1)}$.

No contexto de mobilização social reinante àquela época, a situação vivenciada pelas pessoas com deficiência emergiu como um movimento que problematizava suas questões para inseri-las na arena política, enquanto demanda que exigia resposta da sociedade e do Estado.

Em 1989 o Brasil formalizou a Lei 7.853/89(2), denominada de Política Nacional para Integração da Pessoa Portadora de Deficiência, embora só em 1999 essa lei tenha sido regulamentada através do Decreto 3.298/ $99^{(3)}$

A apreciação pouco cuidadosa dos textos oficiais indica avanços na forma da sociedade lidar e assistir as pessoas com deficiência, o que entre outras causas, está relacionado com modificações da mesma ordem que vinham sendo apontadas por organismos internacionais como a Organização das Nações Unidas e a Organização Mundial de Saúde.

Mas há incoerências entre o discurso contido nas políticas públicas voltadas para os interesses das pessoas com deficiência e as ações concretas que as materializam. Na sociedade brasileira, ainda se fazem presentes, de modo bastante enfático, atitudes de descaso e preconceituosas em relação aos direitos dessas pessoas.

As pessoas com deficiência, no Brasil, somam $14,5 \%^{(4)}$. Ao contrário das demais pessoas, no nosso entendimento, elas nem sempre podem ocupar plenamente os espaços públicos, não pela sua deficiência, mas porque não há acessibilidade suficiente, seja nos transportes, nas ruas, nas edificações, entre outros.

Tendo em vista o exposto, o presente trabalho tem como objetivo refletir sobre o modo como a sociedade brasileira vem se comportando em relação às pessoas com deficiência, tomando como elementos de análise as políticas públicas voltadas a esse segmento e como um dos suportes a essa análise o princípio da inclusão social.

É importante um questionamento acerca das concepções no tocante à deficiência, visto que qualquer pessoa apresenta deficiência em uma determinada área e potencialidade em outras. Por outro lado, o momento em que se procede a esta reflexão é bastante oportuno, tendo em vista a possibilidade política conquistada pela sociedade brasileira, onde o atual governo federal busca avançar para um novo e superior patamar de enfrentamento às desigualdades sociais ${ }^{(5)}$.

Nessa perspectiva, consideramos que esta reflexão tem relevância em um contexto em que é necessária a re-configuração de cenários e de uma sociedade que perceba no paradigma da inclusão social, a possibilidade de crescer e de cumprir seus deveres quanto à cidadania. Nosso esforço se soma a estudos recentes relacionados a melhor aclarar esta questão ${ }^{(6-9)}$.

Abordamos o modo como a sociedade vem se comportando em relação às pessoas com deficiência e repassamos as políticas públicas para esse segmento.

Para fomentar a discussão, a inclusão social foi tomada como processo composto de transformações pequenas e grandes, nos ambientes físicos e na mentalidade das pessoas, inclusive das pessoas com deficiência, para que a sociedade possa se preparar para incluir em seu seio todas as pessoas ${ }^{(10)}$. Partimos também do pressuposto de que uma sociedade democrática e inclusiva é aquela onde suas diversidades são eqüitativamente representadas em todos os setores ${ }^{(11)}$.

\section{ANTECEDENTES INTERNACIONAIS E PESSOAS COM DEFI CI ÊNCIA NO BRASI L}

Algumas culturas por ignorarem a deficiência como uma das características da condição humana ou por despreparo para cuidar das pessoas que apresentavam alguma deficiência, simplesmente as eliminavam do convívio social ou as internavam em instituições caritativas junto com idosos e doentes ${ }^{(10)}$.

A inclusão ou exclusão social das pessoas com deficiência liga-se ao modo como cada sociedade, não só a brasileira, mas a maioria delas, percebe as pessoas diferentes. Isso tem levado ao delineamento de fases distintas.

$\mathrm{Na}$ fase caritativa ou tradicionalista, as pessoas com deficiência, por serem consideradas inválidas e incapazes, são tuteladas e impedidas de se assumirem como sujeitos, tendo que depender da caridade de outros. Na fase reabilitatória, tidas como anormais, elas, tornam-se pacientes da ação de especialistas que intervêm para reabilitá-las e adaptá-las ao padrão de normalidade ${ }^{(12)}$. Nesse último modelo predomina o paternalismo. Isso ocorre de modo particular no Brasil que tem uma sociedade em que o imaginário racista perpassa todas as relações ${ }^{(11)}$.

A fase de autonomia se inicia mais claramente com o movimento pela redemocratização do país e a partir de então, as questões que dizem respeito às pessoas com deficiência se inserem no contexto político e sociocultural.

O que ocorreu no Brasil esteve, de alguma forma, inserido no contexto internacional. Em 1975 a Organização das Nações Unidas (ONU) aprovou a 
Declaração dos Direitos das Pessoas Deficientes onde se define que toda pessoa - independente da diferença cultural, social, ética, de nível mental, emocional e credo - deve ser percebida, compreendida e recebedora das mesmas chances para reivindicar e ter oportunidades reconhecidas para uma vida individual ou social, às das demais pessoas $^{(13)}$. Isso contribuiu para o delineamento de estratégias como a definição do Ano Internacional das Pessoas Deficientes em 1981, a aprovação do Programa de Ação Mundial para Pessoas com Deficiência em 1982 e as Normas sobre a Equiparação de Oportunidades para Pessoas com Deficiência em 1993. A Organização Mundial de Saúde (OMS), em 1997, fixou princípios que dão ênfase ao apoio, aos contextos ambientais e às potencialidades, ao invés da valorização das incapacidades e das limitações das pessoas com deficiência $^{(14)}$.

\section{A POLÍ TI CA NACI ONAL E SEU CONTEXTO}

O Brasil publicou em 1999 o Decreto $3298^{(3)}$ que regulamenta a Lei 7853 de 23/10/89, formalizando a Política Nacional para Integração da Pessoa Portadora de Deficiência. O texto prevê que os órgãos e entidades do poder público devem assegurar à pessoa portadora de deficiência o pleno exercício de seus direitos, inclusive à educação, à saúde, ao trabalho, ao desporto, ao turismo, ao lazer, à previdência social, à assistência social, ao transporte, à edificação pública, à habitação, à cultura. E também o amparo à infância e à maternidade e outros que, decorrentes da Constituição e das leis, propiciem seu bem-estar pessoal, social e

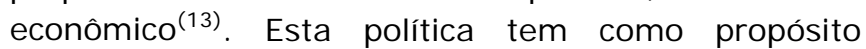
reabilitar a pessoa com deficiência na sua capacidade funcional e de desempenho humano - de modo a contribuir para sua inclusão plena em todas as esferas da vida social ${ }^{(1)}$. Cabe aos gestores do SUS desenvolver, em interface com outros setores, as articulações necessárias e compartilhar responsabilidades para fazer cumprir os propósitos dessa política em nível local, coordenando sua elaboração e execução em consonância com os parâmetros nacionais ${ }^{(14)}$.

Como as políticas públicas estão sujeitas a injunções de toda ordem, em que se destacam, entre outros aspectos, a escassez de recursos, a perspectiva neoliberal do Estado mínimo e questões culturais existentes, esse processo está ainda no início e enfrenta dificuldades.

Já é possível compreender que a deficiência não causa a incapacidade e que ela só se instala plenamente quando são negadas ao indivíduo oportunidades de atendimento médico adequado, de educação e para o exercício do convívio comunitário $^{(12)}$.
Quando uma sociedade exclui a pessoa com deficiência das políticas públicas está praticando injustiça, alimentando uma situação humilhante que degrada a cidadania da pessoa com deficiência, das pessoas mais próximas e da sociedade.

É certo que já ocorreram avanços tecnológicos e no campo da pesquisa biomédica que vêm revolucionando a intervenção em relação a determinados campos das deficiências. Todavia, é fácil observar que espaços, equipamentos e comportamentos da sociedade ainda seguem um padrão que somente atende às necessidades das pessoas tidas como normais.

Embora no Brasil, já se registrem alguns desses avanços, ainda não está enraizada na sociedade uma compreensão que leve a conceber e propor soluções simples para incluir as pessoas com deficiência em todos os espaços. Mesmo que a Constituição de 1988 tenha representado um avanço, no que se refere às pessoas com deficiência as regulamentações foram remetidas a momento posterior. Por outro lado, mesmo que os marcos legais tenham contemplado direitos básicos e essenciais, mantiveram-se idéias e até ações de caráter assistencialista ${ }^{(9)}$.

As ruas, espaços públicos e arquitetura da maioria de nossas cidades evidenciam que as pessoas com deficiência se vêem impedidas de viver com qualidade e autonomia. Isso inclui espaços de lazer, transportes públicos, repartições e passeios e calçadas da maioria de nossas cidades que não estão adaptados às necessidades dessas pessoas.

A Lei $10.048 / 2000$ prevê a adequação de espaços públicos, equipamentos e veículos de transporte coletivo, para as pessoas com deficiência. Os proprietários dos veículos teriam 180 dias após a regulamentação para proceder às adaptações e o Poder Executivo teria o prazo de 60 dias, contado da publicação da lei, 08 de novembro de 2000, para regulamentá-la ${ }^{(13)}$. Convém registrar que o Poder Executivo Federal regulamentou a referida lei em dezembro de 2004, quatro anos depois e não seis meses como estava previsto.

Há problemas graves e que exigem soluções urgentes e antigas que resistem ao tempo e muitas vezes passam despercebidas na sociedade como se não tivessem relevância. Nesse contexto, as pessoas com deficiência têm negado seu direito de circular e de participar dos espaços públicos, o que é algo inconcebível numa sociedade democrática e inclusiva.

São necessárias medidas complexas, é verdade. Mas também é necessário que a sociedade promova medidas simples e imprescindíveis para que se firme no propósito de alterar seus valores culturais em relação às pessoas com deficiência. 


\section{DEFICIÊNCIA COMO FENÔMENO RELACI ONAL E A EQUI PARAÇÃO DE OPORTUNI DADES}

Para alterar paradigmas a mudança na abordagem conceitual é de fundamental importância. Embora pareça simples, uma mudança nesse âmbito deve corresponder a algo profundo e complexo e que sinalize para o surgimento de novos valores sociais.

No Brasil, o texto da Política Pública de Saúde da Pessoa Portadora de Deficiência inspira-se em documento da Organização Mundial de Saúde de 1989, definido deficiência como "toda perda ou anormalidade de uma estrutura ou função psicológica, fisiológica ou anatômica que gere incapacidade para o desempenho de atividade, dentro do padrão considerado normal para o ser humano"(14).

Ao definir pessoa com deficiência tendo como referência o padrão normal, vinculado à noção de perfeição, a idéia central passada é de falta, de carência, de falha ou anormalidade passíveis de identificação, como se toda deficiência fosse possível de ser identificada e representasse falta ou falha no ser humano.

É importante explicitar as contradições e imprecisões existentes nos conceitos, e refletidas na prática, mesmo na atualidade, e que precisam ser mais bem discutidas, para que a deficiência seja compreendida como um fenômeno relacional e não como algo natural.

“A partir da concepção das deficiências como diferenças humanas, e em oposição às práticas corretivas tradicionais, a utilização de instrumentos e artefatos culturais inicia um novo processo que reconstrói funções - como a da linguagem e da comunicação - e promove a acessibilidade ao ambiente e ao contexto social em prol do desenvolvimento humano. Não é o sujeito que precisa adaptar-se à sociedade e sim a sociedade que precisa adaptar-se às especificidades dos indivíduos"(4).

É necessária uma superação dialética de conceitos restritivos e a construção de uma nova denominação que denote um conceito mais abrangente e menos estigmatizador da pessoa que porta uma diferença restritiva, principalmente através da participação ativa e propositiva das pessoas atingidas por estas definições ${ }^{(12)}$. Mas para isso, vale ressaltar, é necessário que os espaços físicos e meios de comunicação sejam acessíveis, bem como os profissionais estejam mais bem preparados.

Por exemplo, em relação à assistência à saúde voltada para as pessoas com deficiência, é necessário mais do que diagnosticar que elas têm um problema que caracteriza uma deficiência. Aspectos socioculturais e legais envolvidos com suas questões de saúde também precisam ser apreendidos ${ }^{(8)}$. Por outro lado, os esforços não devem se centrar em adequar a pessoa à realidade.

Esta questão é particularmente importante para as pessoas surdas. Há relatos indicando dificuldades de comunicação delas com os profissionais de saúde e vice-versa. A defesa pela presença de intérpretes em Língua Brasileira de Sinais(LIBRAS) é um fator facilitador. Embora isso represente um testemunho de respeito à diversidade, foi demonstrado através de pesquisa que a presença do intérprete nos serviços melhora, mas não contribui totalmente para que tais pessoas se sintam compreendidas e incluídas ${ }^{(6)}$.

Partindo do entendimento de que as barreiras de comunicação entre profissionais de saúde e clientes surdos podem prejudicar a assistência prestada, inclusive o diagnóstico e o tratamento, havendo desconforto entre os dois lados envolvidos, alguns autores sugerem que as instituições acadêmicas oportunizem estudos relacionados com 0 atendimento dessas pessoas por profissionais de saúde ${ }^{(8)}$.

Experiências recentes vêm demonstrando que já há no mercado profissionais de saúde com qualificação para o uso da LIBRAS, o que facilita de modo decisivo a comunicação com os $\operatorname{surdos}^{(6)}$

Mas vale ressaltar que, como na mesma categoria estão pessoas com diversos tipos de deficiência, as ações de saúde voltadas para esse segmento devem considerar um mosaico de diferentes necessidades ${ }^{(9)}$.

Mesmo assim, a questão da inclusão social das pessoas com deficiência ainda é particularmente problemática no campo do trabalho, este na verdade, uma confluência da educação e de vários outros.

Determinada pesquisa demonstrou que a deficiência em si não foi fator decisivo na valorização de aspectos positivos e negativos do trabalho por pessoas com e sem deficiência física e que, como os portadores desse tipo de deficiência necessidades especiais, o significado que atribuem ao trabalho remete a aspectos relativos ao ajustamento deles ao ambiente de trabalho. Isso inclui providências para que ocorra e se mantenha a inclusão deles nesse ambiente e na sociedade: programas de treinamento que ultrapassem itens de desempenho funcional e incluam aspectos do relacionamento interpessoal no contexto do trabalho. Defende isto, tendo em vista que esses trabalhadores são mais vulneráveis à perda do emprego devido a suas dificuldades em habilidades sociais ${ }^{(8)}$.

Registram-se várias outras iniciativas que testemunham os avanços recentes relacionados aos direitos das pessoas com deficiência: a criação do Conselho Nacional dos Direitos da Pessoa Portadora de Deficiência (CONADE), cuja incumbência é zelar e coordenar as políticas públicas de atenção às pessoas com deficiência. Este conselho foi instituído através do Decreto 3076 de 01 de junho de 1999(15). Está em 
tramitação no Congresso Nacional o Estatuto da Pessoa com Deficiência, cujo propósito é assegurar a integração e a inclusão social e o pleno exercício dos direitos individuais e coletivos das pessoas que apresentam limitação em suas atividades devido à sua deficiência ${ }^{(16)}$.

Também vale o registro da Lei 10.845 de 05 de março de 2004 que institui no âmbito do Fundo Nacional de Desenvolvimento da Educação (FNDE) o Programa de Complementação ao Atendimento Educacional Especializado às Pessoas Portadoras de Deficiência (PAED). Através desta lei, fica garantida a universalização do atendimento das pessoas com deficiência, em salas especiais, quando sua necessidade exigir isso, bem como, sua inserção progressiva no ensino regular ${ }^{(13)}$. Igualmente importante é o Decreto No. 5.296 (17), de 02 de dezembro de 2004, regulamentando a Lei 10.048, que dá prioridade ao atendimento às pessoas com deficiência, e a Lei No. $10.098^{(18)}$ de 2000, que estabelece normas gerais e critérios básicos para a promoção da acessibilidade das pessoas com deficiência ou com mobilidade reduzida.

O Decreto 5.904./2006 ${ }^{(19)}$ regulamentou a Lei $11.126 / 2005$, que dispõe sobre o direito da pessoa com deficiência visual usuário de cão-guia de ingressar e permanecer em ambientes de uso coletivo acompanhado do animal; a Política Nacional de Saúde da Pessoa Portadora de Deficiência, formalizada pelo Ministério da Saúde em $2007^{(20)}$.

A criação de conselhos e demais órgãos colegiadas, como dispositivos previstos na nova legislação, instâncias colegiadas para efetivação do controle social das políticas públicas, é elemento essencial para que aquelas sejam concebidas, implementadas e analisadas de modo adequado a atender as necessidades dos seus usuários. Ademais, é o controle social que assegura o bom uso do recurso e a pertinência da política pública.

Os conselhos são importantes órgãos aglutinadores das diferentes demandas de segmentos de pessoas com deficiências específicas e de todas as deficiências. Pela sua natureza, exigem a articulação de demandas entre diferentes setores da sociedade e isso fortalece a intervenção social dos segmentos articulados.

É perceptível que a existência da legislação e o fortalecimento de importantes organizações lideradas pelas próprias pessoas com deficiência - que mais e mais se representam por elas mesmas - fortalecem o novo debate sobre a equiparação de oportunidades desse segmento à de toda a população e uma equiparação participativa na melhoria das condições de vida resultante do desenvolvimento social e econômico.

Como o próprio texto oficial afirma, a deficiência não é necessariamente causa de incapacidade. Ocorre que, quando as soluções simples não são aplicadas e quando as práticas institucionais são restritivas, aumenta a probabilidade de os indivíduos com deficiência serem postos cada vez mais em situação de desvantagem. Portanto, caracteriza-se, também, como uma questão de caráter relacional.

\section{CONSI DERAÇÕES FI NAIS}

É possível reconhecer que, em cada época, o modo como as sociedades agiram em relação à pessoa com deficiência foi concebido de acordo com os valores culturais que nortearam cada sociedade, que precisam ser respeitados.

A deficiência já foi tratada como um problema da pessoa, como um fenômeno relacionado à doença e cuja responsabilidade sobre essa pessoa cabia a seus familiares ou a entidades especiais. Felizmente circunstâncias políticas permitiram que a deficiência começasse a ser compreendida como uma questão social. Daí que atualmente passa-se a compreender a inclusão social da pessoa com deficiência como uma necessidade social que permeia o campo da ética e da cidadania. Há atualmente a crescente preocupação com o respeito aos direitos humanos. Também avança a compreensão da deficiência como um fenômeno relacional.

Mesmo assim, as formas de tratamento disponíveis precisam avançar bastante para assegurar atividades muito simples da vida cotidiana para que as pessoas com deficiência possam buscar os meios para combater a natureza de sua exclusão social.

É perceptível que a existência da legislação e o fortalecimento de importantes organizações lideradas pelas próprias pessoas com deficiência - que se representam por elas mesmas - fortaleceram o novo debate sobre a equiparação de oportunidades desse segmento à de toda a população.

\section{REFERÊNCI AS}

1. Conselho Nacional de Saúde, Ministério da Saúde. O desenvolvimento do SUS: avanços, desafios e reafirmação dos seus princípios. Brasília (Brasil): Ministério da Saúde; 2002. 61 p.

2. Lei No. 7.853/89 de 24 de outubro de 1989. Dispõe sobre o apoio às pessoas portadoras de deficiência, sua integração social, sobre a Coordenadoria Nacional para Integração da Pessoa Portadora de Deficiência - Corde, institui a tutela jurisdicional de interesses coletivos ou difusos dessas pessoas, disciplina a atuação do Ministério Público, define crimes, e dá outras providências. Diário Oficial da União (Brasília). 1989 Oct 25.

3. Casa Civil, Presidência da República. Decreto № 3.298, de 20 de dezembro de 1999 [Internet]. Brasília (Brasil): Presidência da República; 1999 [cited 2009 may 20]. Available from http: //www.planalto.gov.br/ccivil/decreto/d3298.htm 
4. Ministério da Saúde. Secretaria de Atenção à Saúde. Departamento de Ações Programáticas Estratégicas. Coordenação da Área Técnica Saúde da Pessoa com Deficiência. 2nd ed. Brasília: Ministério da Saúde; 2007.

5. Secretaria de Comunicação de Governo e Gestão Estratégica da Presidência da República [Internet]. Brasília: Presidência da República (BR) [update 2003 feb 17, cited 2009 may 26]. Mensagem ao Congresso Nacional 2003. Available from: http://www.presidencia.gov.br/noticias/publicacoes/ mens_cong2003/.

6. Chaveiro N, Barbosa MA. Assistência ao surdo na área de saúde como fator de inclusão social. Rev. esc. enferm. USP. 2005;39(4):417-22.

7. Pereira CA, Del Prette A, Del Prette ZAP. Qual o significado do trabalho para as pessoas com e sem deficiência física? PsicoUSF [Internet]. 2008 [cited 2009 may 20]; 13(1): 105-14.

8. Chaveiro N, Barbosa MA e Porto CC. Revisão de literatura sobre o atendimento ao paciente surdo pelos profissionais de saúde. Rev. esc. enferm. USP. 2008; 42(3): 578-83.

9. Bernardes LCG, Maior IMML, Spezia $\mathrm{CH}$, Araújo TCCF. Ciên. saúde coletiva. 2009; 14(1): 31-8.

10. Sassaki K. Inclusão: construindo uma sociedade para todos. 5th ed. Rio de Janeiro: WVA; 2003.

11. Munanga K. Saúde e diversidade. Saúde soc. 2007; 16(2): 13-18.

12. Shirley S, Marli V, organizadoras. Políticas públicas: educação, tecnologias e pessoas com deficiências. Campinas: Mercado de Letras; 2003.

13. Assembléia Legislativa de São Paulo. Política pública da pessoa portadora de (D)eficiência: legislação federal, estadual, municipal. São Paulo: Assembléia Legislativa de São Paulo; 2004.

14. Ministério da Saúde. Manual de legislação em saúde da pessoa portadora de deficiência. Brasília: Ministério da Saúde; 2003.

15. Casa Civil, Presidência da República. Decreto № 3.076, de 1을 de junho de 1999 [Internet]. Brasília (Brasil): Presidência da República; 1999 [cited 2009 may 20]. Available from http://www.planalto.gov.br/ccivil_03/decreto/D3076. htm.

16. Senado Federal. Projeto de Lei No. 06/2003 de Paulo Paim sobre o Estatuto da Pessoa Portadora de Deficiência. Brasília (Brasil): Senado Federal; 2003.

17. Casa Civil, Presidência da República. Decreto № 5.296, de 2 de dezembro de 2004 [Internet]. Brasília (Brasil): Presidência da República; 2004 [cited 2009 may 20]. Available from http://www.planalto.gov.br/ccivil_03/_Ato20042006/2004/Decreto/D5296.htm.

18. Casa Civil, Presidência da República. Lei № 10.098, de 19 de dezembro de 2000 [Internet]. Brasília (Brasil): Presidência da República; 2000 [cited 2009 may 20]. Available from http: //www.planalto.gov.br/CCIVIL/LEIS/L10098.htm 19. Casa Civil, Presidência da República. Lei № 11. 126, de 27 de junho de 2005 [Internet]. Brasília (Brasil): Presidência da República; 2005 [cited 2009 may 20]. Available from:

http://www.planalto.gov.br/ccivil_03/_ato20042006/2005/Lei/L11126.htm.

20. Secretaria de Saúde do Ceará. Portaria Nº 1.784/2003. Fortaleza (Brasil): Secretaria de Saúde do Ceará; 2003.

Artigo recebido em 29.03.08.

Aprovado para publicação em 25.05.09. 